\title{
Microstructure and Mechanical Properties of Ultrafine Structured Al-4wt\%Cu-(2.5-10) vol.\%SiC Nanocomposites Produced by Powder Consolidation Using Powder Compact Extrusion
}

\author{
Amro A.Gazawi ${ }^{1}$, Brian Gabbitas ${ }^{2}$, Deliang Zhang ${ }^{3}$, Charlie Kong ${ }^{4}$, Paul Munroe $^{5}$ \\ ${ }^{1,2}$ Waikato Centre of Advanced Materials (WaiCAM), School of Engineering, The University of \\ Waikato, Hamilton, New Zealand \\ ${ }^{3}$ Shanghai Jaio Tong University, School of Materials Science and Engineering, 800 Dongchuan Road, \\ 200240, Shanghai , China \\ ${ }^{4,5}$ Electron Microscopy Unit, The University of New South Wales, Sydney, Australia
}

Correspondence should be addressed to: Amro A. Gazawi; ag73@students.waikato.ac.nz

Received date: 15 April 2014; Accepted date: 29 May 2014; Published date: 4 December 2015

Academic Editor: Sri Bandyopadhyay

Copyright @ 2015. Amro A.Gazawi, Brian Gabbitas, Deliang Zhang, Charlie Kong, Paul Munroe. Distributed under Creative Commons CC-BY 4.0

\begin{abstract}
Ultrafine structured Al-4wt. \%Cu- (2.5-10) vol. \% SiC nanocomposites were produced by high energy mechanical milling of a mixture of $\mathrm{Al}$ and $\mathrm{Cu}$ powders and $\mathrm{SiC}$ nano-powder to produce nanocomposites powders, followed by consolidation of the powders using powder compact extrusion (PCE). Scanning and transmission electron microscopy as well as tensile testing were used to characterize the extruded nanocomposite bars. Increasing the volume fraction of SiC nanoparticles from 2.5 to 5.0 causes the yield strength, ultimate tensile strength and microhardness of the nanocomposite to increase from $98 \mathrm{MPa}, 168 \mathrm{MPa}$ and $104 \mathrm{HV}$ to $391 \mathrm{MPa}, 400 \mathrm{MPa}$ and $153 \mathrm{HV}$, showing the effectiveness of $\mathrm{SiC}$ nanoparticles and microstructural refinement in strengthening the material. However, the ductility decreases from $6.8 \%$ to $2 \%$, possibly due to the existence of SiC nanoparticle agglomerates in the $\mathrm{Al}-4 \mathrm{wt} \% \mathrm{Cu}-5 \mathrm{vol} . \% \mathrm{SiC}$ nanocomposite. The ultrafine structured $\mathrm{Al}-4 \mathrm{wt} \% \mathrm{Cu}-(7.5$ and 10)vol.\%SiC nanocomposite bars fractured prematurely during tensile testing. The possible reason for this may be the existence of $\mathrm{SiC}$ nanoparticles agglomerates in their microstructure.
\end{abstract}

Keywords: Aluminium alloy matrix nanocomposite, powder metallurgy, mechanical properties, microstructure.

\section{Introduction}

Al alloy matrix composites (AMCs) synthesized using powder metallurgy have been studied widely over several decades, due to the potential of such materials to have excellent mechanical properties such as high wear resistance, high strength and

Cite this Article as: Amro A.Gazawi, Brian Gabbitas, Deliang Zhang, Charlie Kong, Paul Munroe (2015), " Microstructure and Mechanical Properties of Ultrafine Structured Al-4wt\%Cu-(2.5-10) vol.\%SiC Nanocomposites Produced by Powder Consolidation Using Powder Compact Extrusion", Journal of Research in Nanotechnology, Vol. 2015 (2015), Article ID 928417, DOI: 10.5171/2015.928417 
improved modulus, as well as low density, which are all highly desirable for aerospace and automotive applications ${ }^{1-13}$. By reducing the sizes of ceramic particles in AMC's to nanometer range $(<100 \mathrm{~nm})$, there is a potential for offering higher strength and fracture toughness. In the fabrication of AMNCs, one of the challenges is the difficulty of dispersing nanometre sized ceramic particles homogeneously in the aluminium alloy matrix. One way of overcoming this difficulty is to produce AMNC powders with ceramic nanoparticles homogenously dispersed in the $\mathrm{Al}$ or $\mathrm{Al}$ alloy matrix of each of the powder particles by high energy mechanical milling (HEMM) of mixtures of metallic powders and the ceramic nanopowders ${ }^{3,6,8,14}$.The nanocomposite powders can be subsequently consolidated using severe plastic deformation processes such as powder compact forging and powder compact extrusion to produce near net shaped components or structural members ${ }^{2,7-9}$. This approach has been used by Hesabi et al. ${ }^{11}$ who synthesised nanostructured $\mathrm{Al}-5 \mathrm{vol} . \% \mathrm{Al}_{2} \mathrm{O}_{3}$ nanocomposite powder by HEMM, and consolidated the milled nanocomposite powder into bars by powder compact extrusion. Their study showed that the ultrafine grained structure of the $\mathrm{Al}$ matrix coupled with the $\mathrm{Al}_{2} \mathrm{O}_{3}$ nanoparticles produced the nanocomposite bars with a strength of $356 \mathrm{MPa}$ and good ductility.

On the other hand, Ogel et al. ${ }^{13}$ used simple mixing of $\mathrm{Al}, \mathrm{Cu}$, and $\mathrm{SiC}$ powders and hot pressing to produce $\mathrm{Al}-5 \mathrm{wt} \% \mathrm{Cu}-(15,30)$ vol.\%SiC metal matrix composites reinforced with micrometer sized $\mathrm{SiC}$ particles. They found that the strength of the material was improved with increasing amounts of $\mathrm{SiC}$ particles, but the ductility of the material was clearly reduced. The microstructural examination also revealed that the $\mathrm{SiC}$ particles were not homogenously distributed in the Al alloy matrix, showing the difficulty with homogenously dispersing $\mathrm{SiC}$ particles even in the fabrication of AMCs using powder metallurgy.

In this study, we utilised the approach of synthesizing nanostructured $\mathrm{Al}-4 \mathrm{wt} . \% \mathrm{Cu}-$ $(2.5-10) \%$ SiC nanocomposite powders using HEMM, followed by consolidation of the milled nanocomposite powders by cold pressing and hot powder compact extrusion to obtain bulk ultrafine structured nanocomposite samples with a uniform distribution of SiC nano particles. The aim of the study is to elucidate the effect of the volume fraction of the $\mathrm{SiC}$ nanoparticles on the microstructure and mechanical properties of bulk ultrafine structured $\mathrm{Al}-4 \mathrm{wt} . \quad \% \mathrm{Cu}-(2.5-10) \% \mathrm{SiC}$ nanocomposites.

\section{Experimental Procedure}

Preparation of the Powder

In this study, the aluminium powder was reinforced with 2.5, 5, 7.5, and 10 vol.\% of $\mathrm{SiC}$ nanoparticles. The powders used were; Al (99.7\% pure; mean particle size: $40 \mu \mathrm{m})$, and $\mathrm{Cu}(99.7 \%$ pure; particle sizes $<63 \mu \mathrm{m})$ powders, SiC nanopowder $(99.5 \%$ pure, particle sizes $<100 \mathrm{nmm}$ ), and $1 \mathrm{wt} \%$ of stearic acid which worked as a process control agent (PCA).

\section{Preparation of the nanocomposites}

To produce the nanocomposite powders, the powders were first mixed under argon for 6 hours with a Restch PM100 planetary ball mill and a rotational speed of $100 \mathrm{rpm}$. Then, the powder mixture was milled for a net time of 12 hours with a rotational speed of 400rpm using the same ball mill.

The nanocomposite powders produced were compacted by using uniaxial pressing at room temperature for 5 minutes under a pressure of $1000 \mathrm{MPa}$ with a cylindrical H13 steel die (internal diameter: $25 \mathrm{~mm}$ ). The powder compacts were heated to 500 ${ }^{\circ} \mathrm{C}$ using induction heating under argon, and then extruded to produce cylindrical bars with diameter of $8 \mathrm{~mm}$. The extrusion cylinder speed was $7.7 \mathrm{~mm} / \mathrm{s}$.

\section{Characterization}

The density of the extruded bars was measured using Archimedes method. Flat dog-bone shaped tensile test specimens with a gauge length of $20 \mathrm{~mm}$ were cut from the extruded bars using an electrical discharge machine (EDM) wire cutter, and 
tested at room temperature using an Instron 4204 testing machine with a strain rate of $1.8 \times 10-4 \mathrm{~s}^{-1}$. Scanning electron microscopy (SEM), transmission electron microscopy (TEM) and X-ray diffractometry (XRD) were used to characterize the microstructure of the extruded bars and fractured tensile test specimens. The microhardness of the extruded bars was measured using a Vickers microhardness tester with a load of 25-g and a loading duration of 15-s.

\section{Results and Discussion}

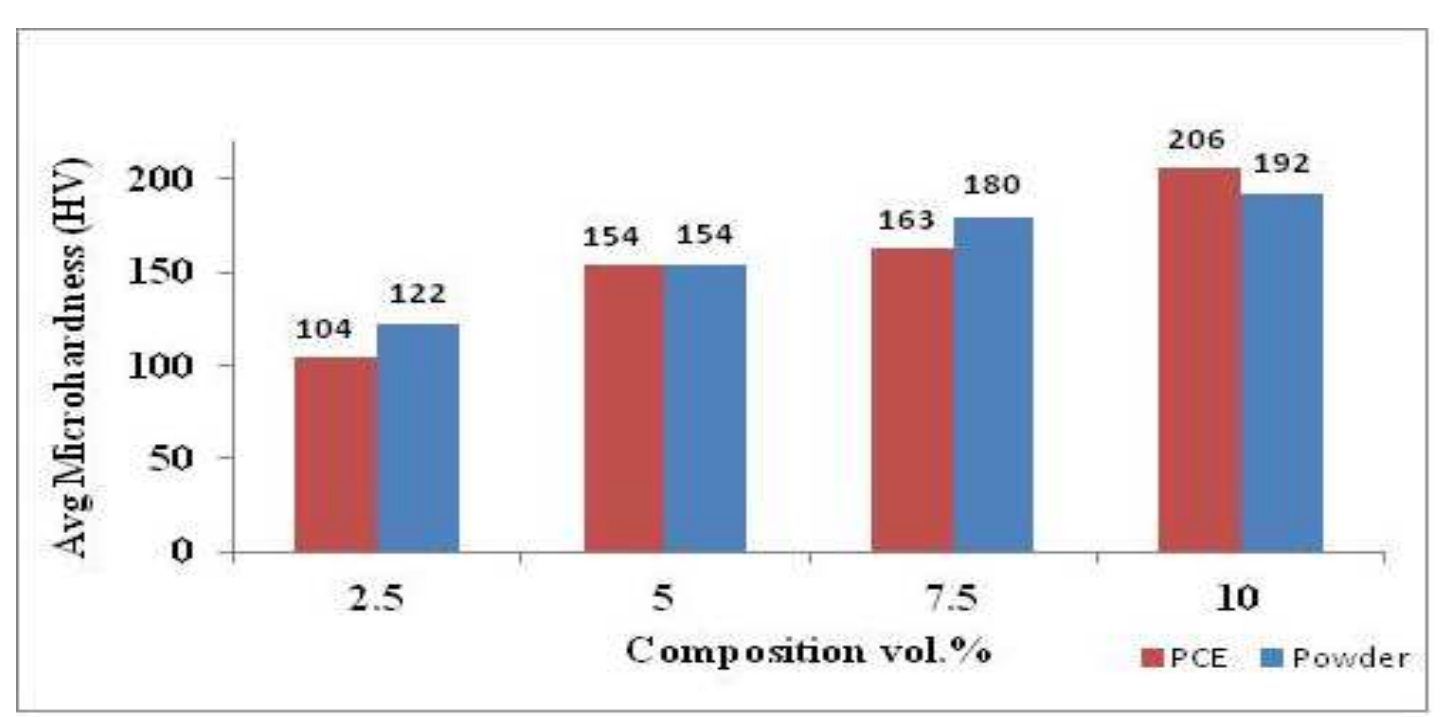

The microhardness of samples produced by powder compact extrusion (PCE) was measured and an average was taken of 15 indents. The average microhardness of the Al-4wt.\%Cu-(2.5-10) vol. \%SiC nanocomposite bars produced by PCE increased from $104 \mathrm{HV}$ to $205 \mathrm{HV}$ with increasing volume fraction of $\mathrm{SiC}$ nanoparticles from 2.5 to $10 \%$. This can be compared with the microhardness of the milled nanocomposite powders, which increased from $122 \mathrm{HV}$ to $192 \mathrm{HV}$, as shown in Fig.1.

\section{Figure 1: Microhardness for $\mathrm{Al}-4 \mathrm{wt} \% \mathrm{Cu}-(2.5-10) v o l . \% S i C$ nanocomposites bars produced by PCE.}

Fig. 2 shows the relative density of the Al4wt.\%Cu-(2.5-10) vol. \% $\quad \mathrm{SiC}$ nanocomposite powder compacts and extruded bars produced as a function of the volume fraction of $\mathrm{SiC}$ nanoparticles. The theoretical density of the material components of the composite was used to calculate the relative density of the powder compacts and extruded bars using the rule of mixtures.

From Fig.2, it can be seen that the relative density of the powder compacts decreased significantly with increasing the $\mathrm{SiC}$ nanoparticle contents from 2.5 to 5 vol. \% and then changed little with further increase in the $\mathrm{SiC}$ nanoparticles to $10 \mathrm{vol}$. $\%$. This is likely due to the increased hardness of the nanocomposite powder particles, produced by milling, with increasing volume fraction of the hard $\mathrm{SiC}$ nanoparticles within the matrix. The relative density of the extruded bars was fairly high, being in the range of 98.5-99.6 $\%$. 


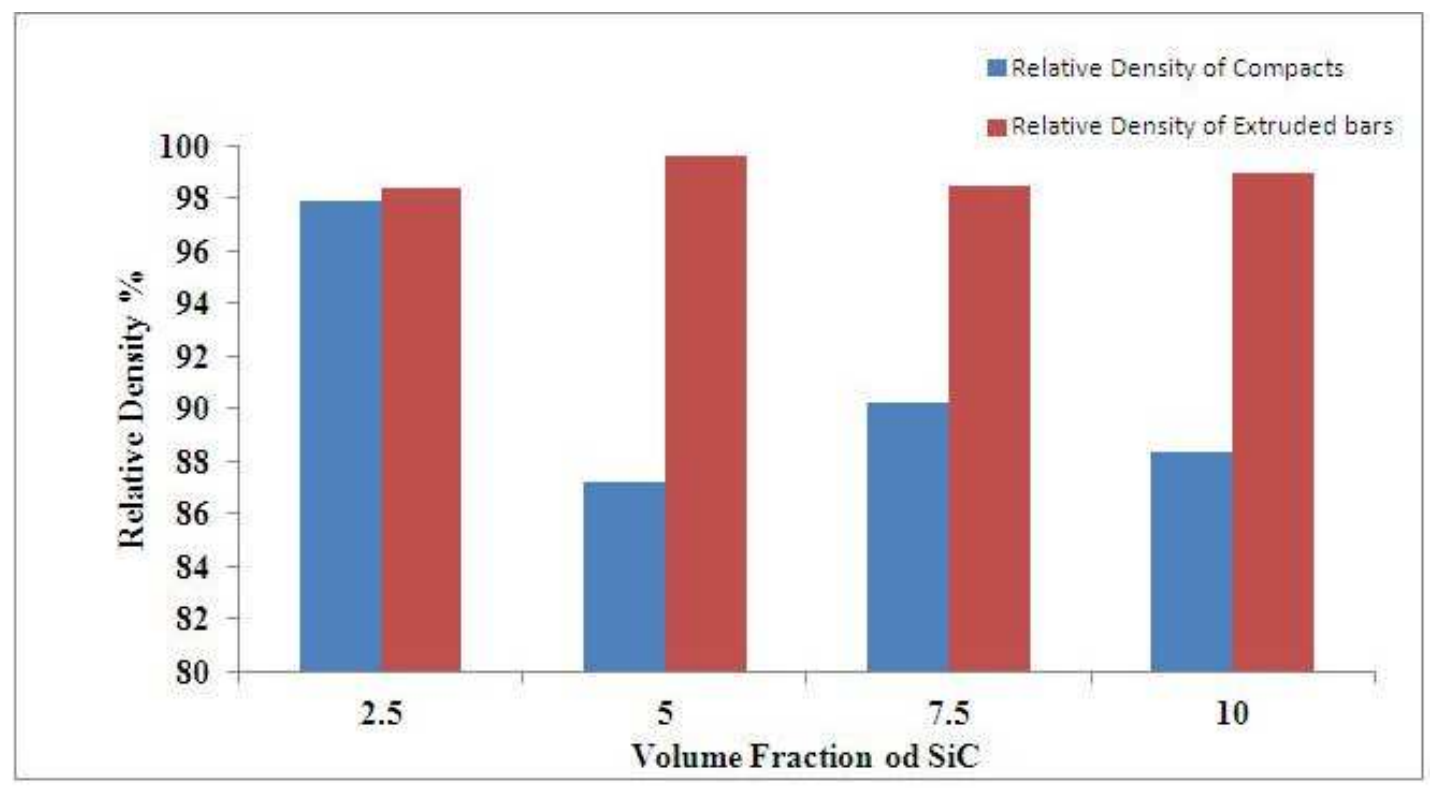

Figure 2: The relative density of the $\mathrm{Al}-4 \mathrm{wt} \% \mathrm{Cu}-\left(2.5-10 \_v o l . \% \mathrm{SiC}\right.$ nanocomposite powder compacts and extruded bars.

During the process of milling mixtures of $\mathrm{Al}$ powder with $4 \mathrm{wt} \% \mathrm{Cu}$ and $2.5 \mathrm{vol} . \% \mathrm{SiC}$ nanoparticles together with 1wt\%PCA, coarse powder particles with sizes in the range of 20-150 $\mu \mathrm{m}$ formed after 12 hours of milling. When the volume fraction of $\mathrm{SiC}$ nanoparticles increased to $5 \%$, the nanocomposite powder particle sizes were in the range of $10-90 \mu \mathrm{m}$ after 12 hours of milling. When the volume fraction of $\mathrm{SiC}$ nanoparticles increased to $7.5 \%$, the nanocomposite powder particle sizes were in the range of 5-120 $\mu \mathrm{m}$ after 12 hours of milling. When the volume fraction of $\mathrm{SiC}$ nanoparticles increased to $10 \%$, the nanocomposite powder particle sizes were in the range of 5-70 $\mu \mathrm{m}$ after 12 hours of milling, as can be seen in Figure 3.

Figure 4 shows typical SEM micrographs of the longitudinal sections of the extruded bars. It was clear that the extruded bars were almost fully dense, with the volume fraction of pores less than 1\%. The clear discrepancy between the density of the extruded bars implied by the SEM examination and that measured using the Archimedes' method is caused by an error in the calculation of the theoretical density of the extruded bars using the rule of mixture, since $\mathrm{Al}$ and $\mathrm{Cu}$ formed a solid solution during milling and consolidation. Fig.5 shows the energy dispersive X-Ray (EDX) elemental mapping of $\mathrm{Cu}$ and $\mathrm{Si}$ and of the longitudinal sections of the Al$4 \mathrm{wt} \% \mathrm{Cu}-(2.5$ and 10$)$ vol. $\% \mathrm{SiC}$ nanocomposite extruded bars. From the elemental mappings of $\mathrm{Si}$ and $\mathrm{Cu}$, it was clear that the majority of the SiC nanoparticles and $\mathrm{Cu}$ were homogeneously distributed throughout the Al matrix. However, a small volume fraction of the $\mathrm{SiC}$ nanoparticles still existed in the Al matrix as agglomerates with sizes in the range of 2-7 $\mu \mathrm{m}$. Un dissolved $\mathrm{Cu}$ particles were also occasionally observed in the microstructure of the $\mathrm{Al}-4 \mathrm{wt} \% \mathrm{Cu}-$ 10vol.\%SiC extruded bars. 


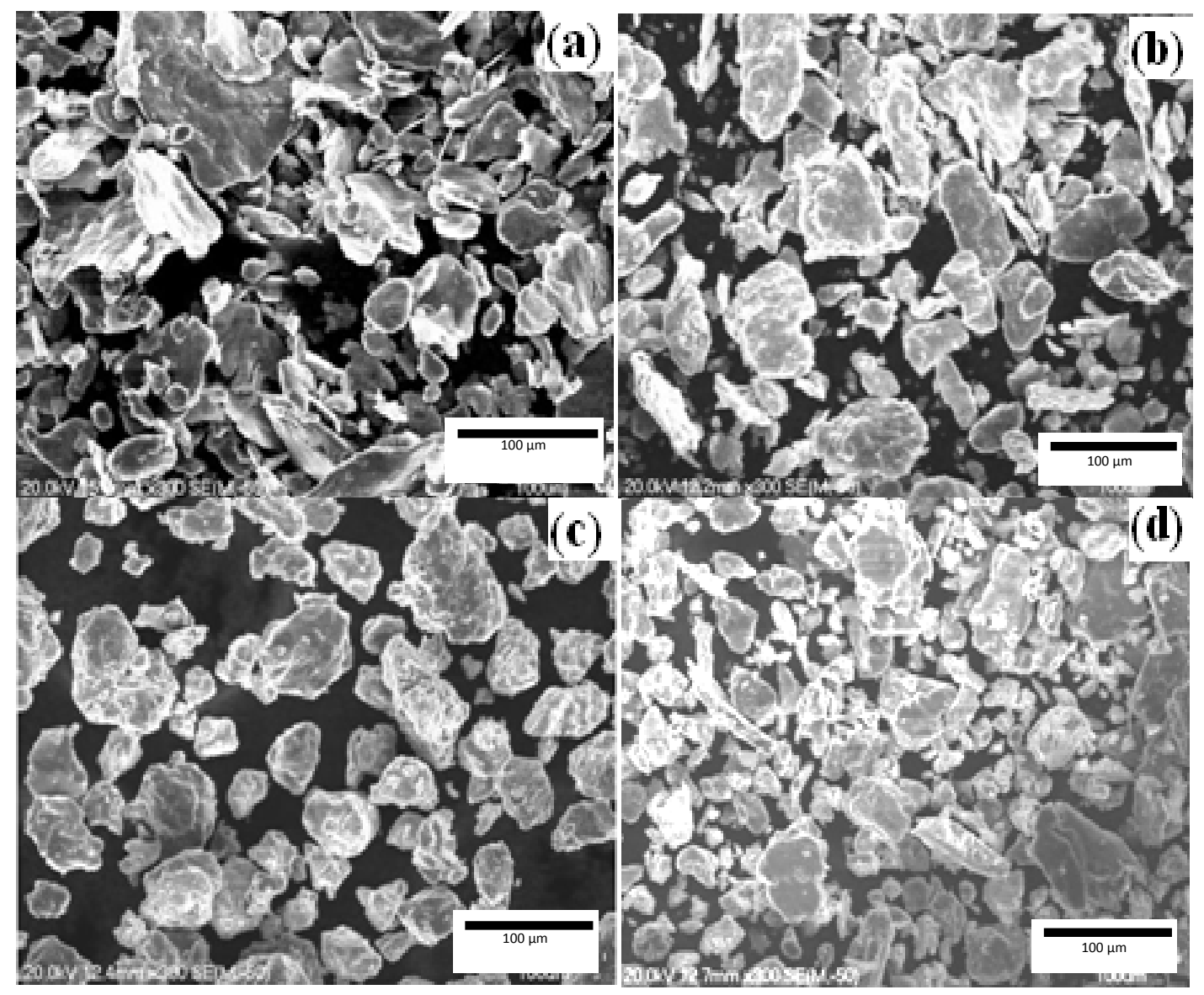

Figure 3: SEM micrographs of $\mathrm{Al}-4 \mathrm{wt} \% \mathrm{Cu}-\mathrm{SiC}$ nanocomposites powder particles produced by 12 hours of milling with 1 wt\% PCA:(a) $2.5 \mathrm{vol. \% SiC,} \mathrm{(b)} 5 \mathrm{vol. \% SiC,} \mathrm{(c)}$ 7.5vol.\%SiC, (d) $10 \mathrm{vol} . \%$ SiC. 


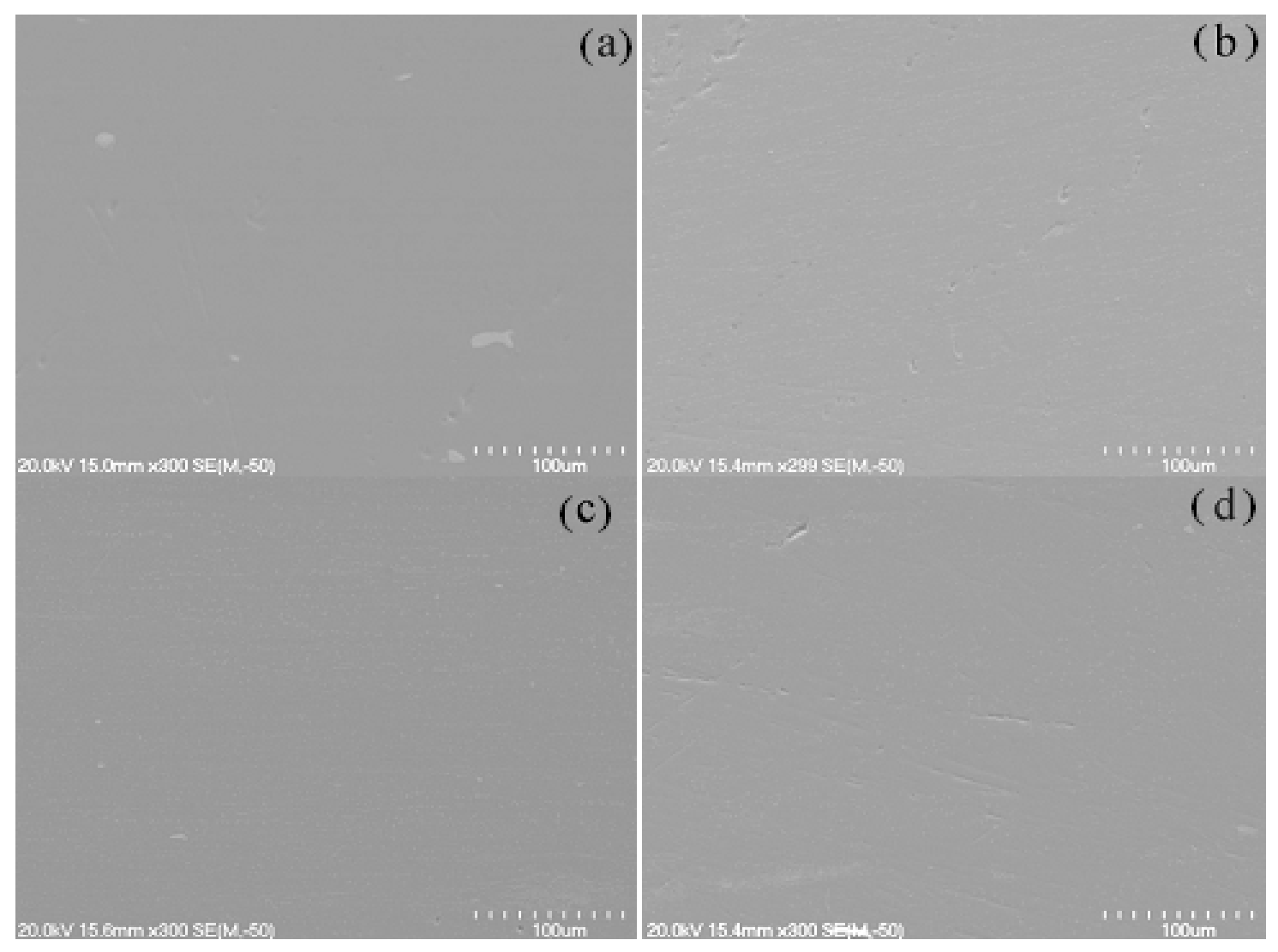

Figure 4: SEM micrographs of the longitudinal cross-sections of the Al-4wt.\%Cu-(2.5-10) vol. \%SiC nancomposite bars produced by powder compact extrusion: (a)Al-4wt.\%Cu2.5vol.\%SiC ; (b) Al-4wt.\%Cu-5vol.\%SiC ; (c) Al-4wt.\%Cu-7.5vol.\%SiC ; and (d) Al4wt.\%Cu-10vol.\%SiC. 

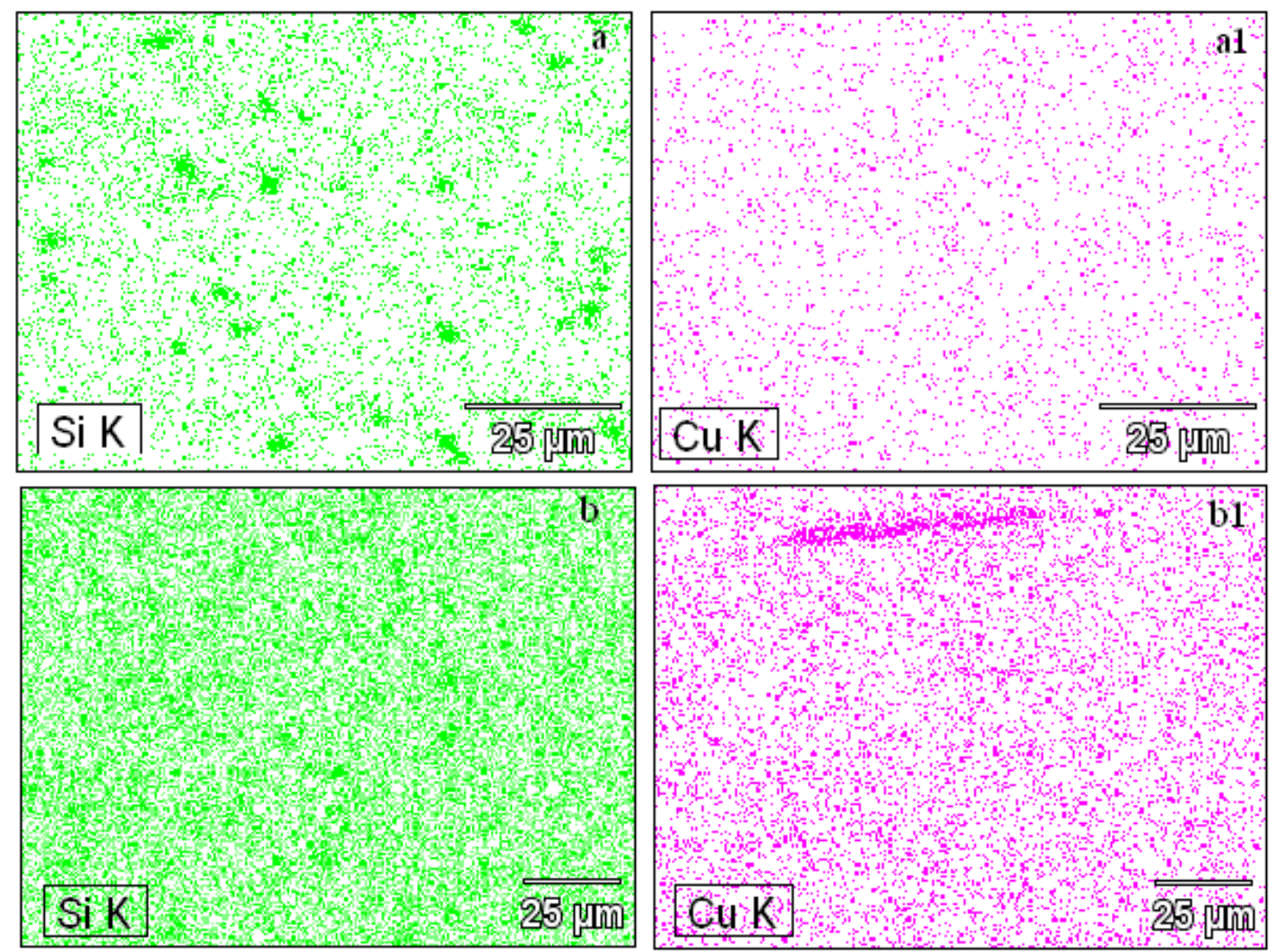

Figure 5: EDX elemental mappings of $\mathrm{Si}$ and $\mathrm{Cu}$ in the $\mathrm{Al}-4 \mathrm{wt} . \% \mathrm{Cu}-(2.5$ and 10$)$ vol. \%SiC nancomposite bars produced by powder compact extrusion: (a) Si distribution in Al-

4wt.\%Cu-2.5vol.\%SiC ; (a1)Cu distribution in Al-4wt.\%Cu-2.5vol.\%SiC ; (b) Si distribution in $\mathrm{Al}-4 \mathrm{wt} \% \mathrm{Cu}-10 \mathrm{vol} . \% \mathrm{SiC}$; and (b1) Cu distribution in $\mathrm{Al}-4 \mathrm{wt} \% \mathrm{Cu}-$ 10vol.\%SiC.

Figure 6 shows XRD patterns of Al4wt\%Cu-(2.5-10) vol.\%SiC nanocomposite cylindrical bars produced by PCE. The XRD patterns show strong Al peaks with weak $\mathrm{SiC}$ and $\mathrm{Cu}$ peaks, due to the small sizes and volume fractions of $\mathrm{SiC}$ and $\mathrm{Cu}$ particles. The average grain sizes and the lattice strain of the Al-4wt\%Cu-(2.5-10)vol.\%SiC nanocomposites cylindrical bars were estimated based on the broadening of the XRD peaks and using the Williamson-Hall method (Figure 7). Based on the Williamson-Hall method (Figure 7), the estimated average grain size and lattice strain of the Al- $4 \mathrm{wt} \% \mathrm{Cu}-2.5 \mathrm{vol} . \% \mathrm{SiC}$ nanocomposites were $250 \mathrm{~nm}$ and $0.39 \%$, respectively. With increasing volume fraction of $\mathrm{SiC}$ nanoparticles to $5 \%$, the grain size and lattice strain changed to 500 $\mathrm{nm}$ and $0.37 \%$, respectively. For Al$4 \mathrm{wt} \% \mathrm{Cu}-7.5 \mathrm{vol} \% \mathrm{SiC}$ nanocomposites, the grain size and lattice strain were $1250 \mathrm{~nm}$ and $0.36 \%$, respectively. For $\mathrm{Al}-4 \mathrm{wt} \% \mathrm{Cu}-$ $10 \mathrm{vol} . \% \mathrm{SiC}$ nanocomposites, the grain size and lattice strain were $1666 \mathrm{~nm}$ and $0.42 \%$, respectively. The average grain size increased with increasing volume fraction of the $\mathrm{SiC}$ nanoparticles in the nanocomposite, while the lattice strain remained in the same range. This is due to the thermal stability of the microstructure of the Al-4wt\%-(2.5-10)vol.\% SiC matrix of the nanocomposite which increases with increasing volume fraction of the $\mathrm{SiC}$ nanoparticles. This enhances the Zenerdrag effect of nanoparticles to resist the movement of grain boundaries. This effect leads to a slower rate of microstructural coarsening with increased content of $\mathrm{SiC}$ nanoparticles during powder compact extrusion. Also, the carbide nanoparticles located throughout the composite 
microstructure should be obstacles for dislocation movement through the grain and more energy is needed to induce diffusion processes for materials with higher nanoparticles inclusions. This explains why some crystallite growth were observed at low nano-SiC contents ${ }^{15}$.

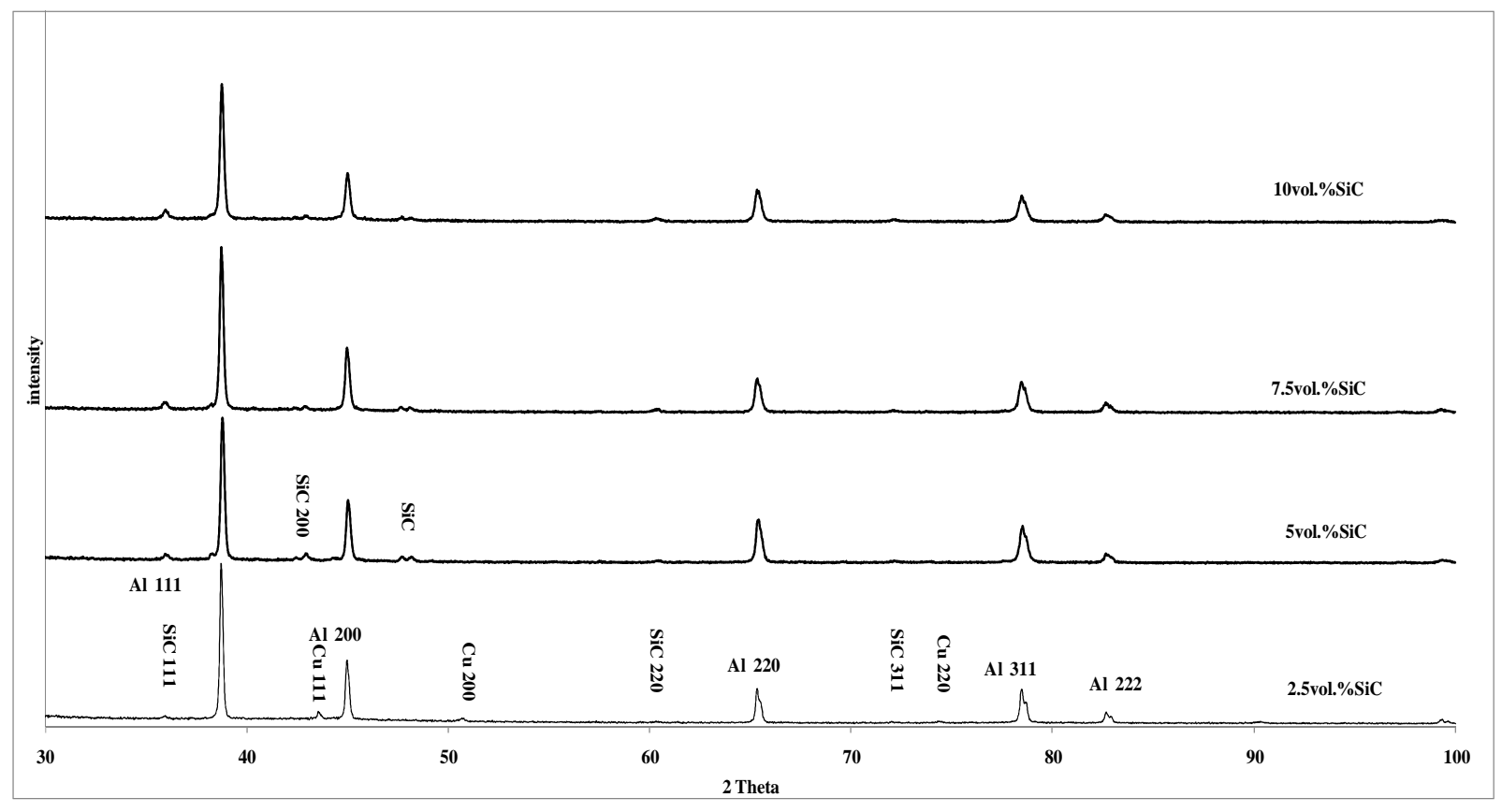

Figure 6: X-ray diffraction patterns of the extruded bars of the Al-4wt.\%Cu-(2.5-10) vol. $\%$ SiC nanocomposites.

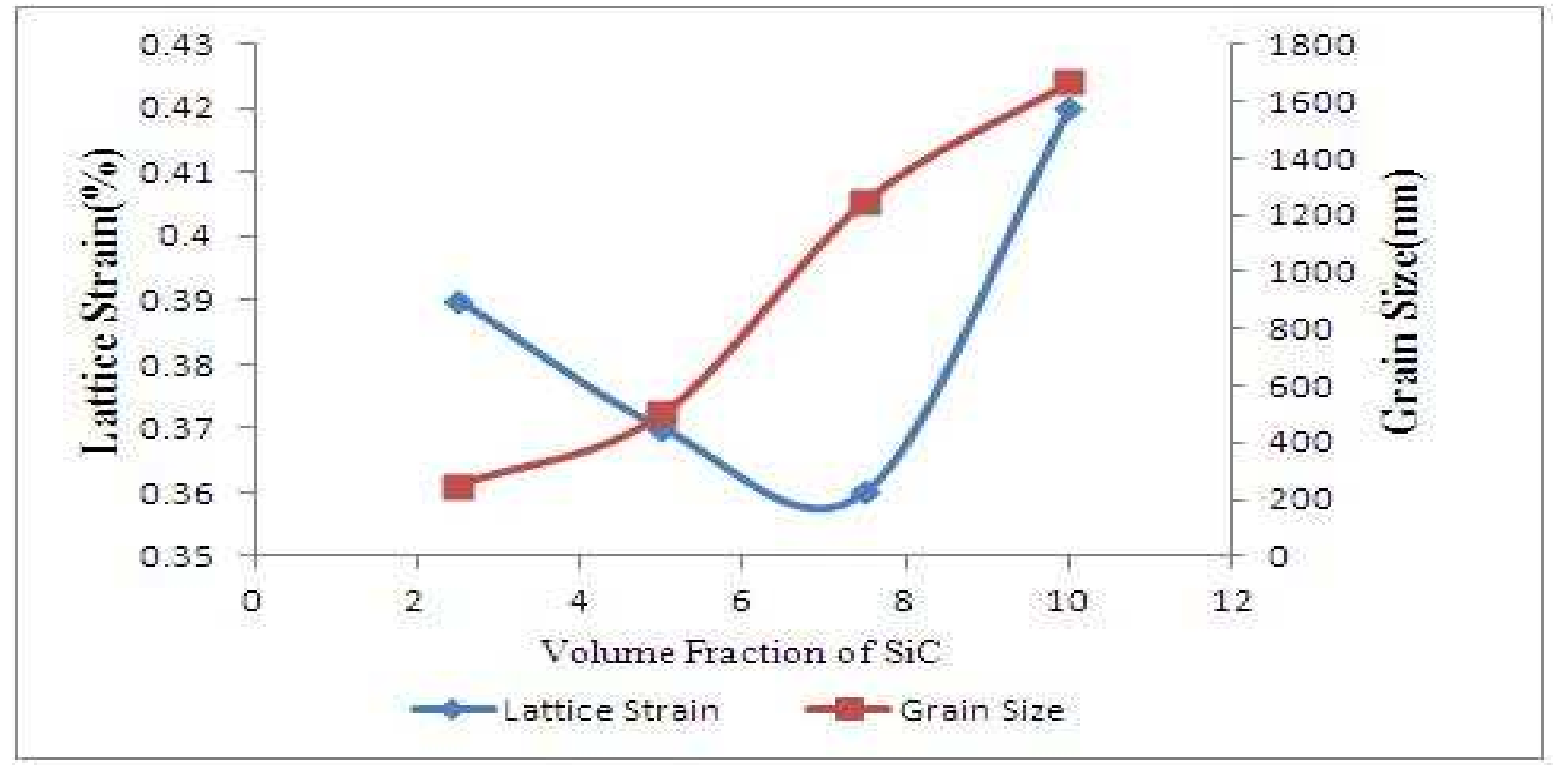

Figure 7: Grain size and lattice strain of the $\mathrm{Al}-4 \mathrm{wt} \% \mathrm{Cu}-(2.5-10) v o l . \% \mathrm{SiC}$ nanocomposites bars produced by PCE as a function of the volume fraction of SiC nanoparticles. 
TEM was utilised to examine the microstructures of the Al-4wt\%Cu-(2.510)vol\%SiC nanocomposite bars produced by PCE. As shown by the TEM bright field image and dark field images shown in Figure 8, the Al-4wt\%Cu-(2.5-10)vol\%SiC nanocomposite extruded bars had an ultrafine grained (UFG) microstructure consisting of $\mathrm{Al}$ grains with sizes ranging $100-800 \mathrm{~nm}$ for $\mathrm{Al}-4 \mathrm{wt} \% \mathrm{Cu}-2.5 \mathrm{vol} . \% \mathrm{SiC}$, 200-600 nm for Al-4wt\%Cu-5vol\%SiC, 100-500 nm for $\mathrm{Al}-4 \mathrm{wt} \% \mathrm{Cu}-7.5 \mathrm{vol} \% \mathrm{SiC}$, and $50-300 \mathrm{~nm}$ for $\mathrm{Al}-4 \mathrm{wt} \% \mathrm{Cu}-10 \mathrm{vol} \% \mathrm{SiC}$. This shows that the average grain size estimated using the broadening of the XRD peaks along with Williamson-Hall method (Figure 7) is clearly bigger than the average Al grain size observed by TEM. This difference is likely due to an underestimate of the broadness of the XRD peaks. The TEM examination also shows that the $\mathrm{Al}$ grains contained a high density of dislocations. Figure 9 shows typical selected area diffraction patterns (SADPs) corresponding to the TEM bright field images shown in Figure 8. The SADPs show diffraction rings of $\mathrm{Al}\{111\},\{200\},\{220\}$, and $\{222\}$ planes, and weak diffraction spots of $\mathrm{SiC}$ nanoparticles. This confirms that $\mathrm{SiC}$ nanoparticles were incorporated into the microstructure of the $\mathrm{Al}-4 \mathrm{wt} \% \mathrm{Cu}$ (2.5-10)vol.\% SiC nanocomposite. The contrast showing the $\mathrm{SiC}$ nanoparticles was not very clear due to the very small size of $\mathrm{SiC}$ nanoparticles and the heavy contrast of the $\mathrm{Al}$ matrix grains containing a high density of dislocations.

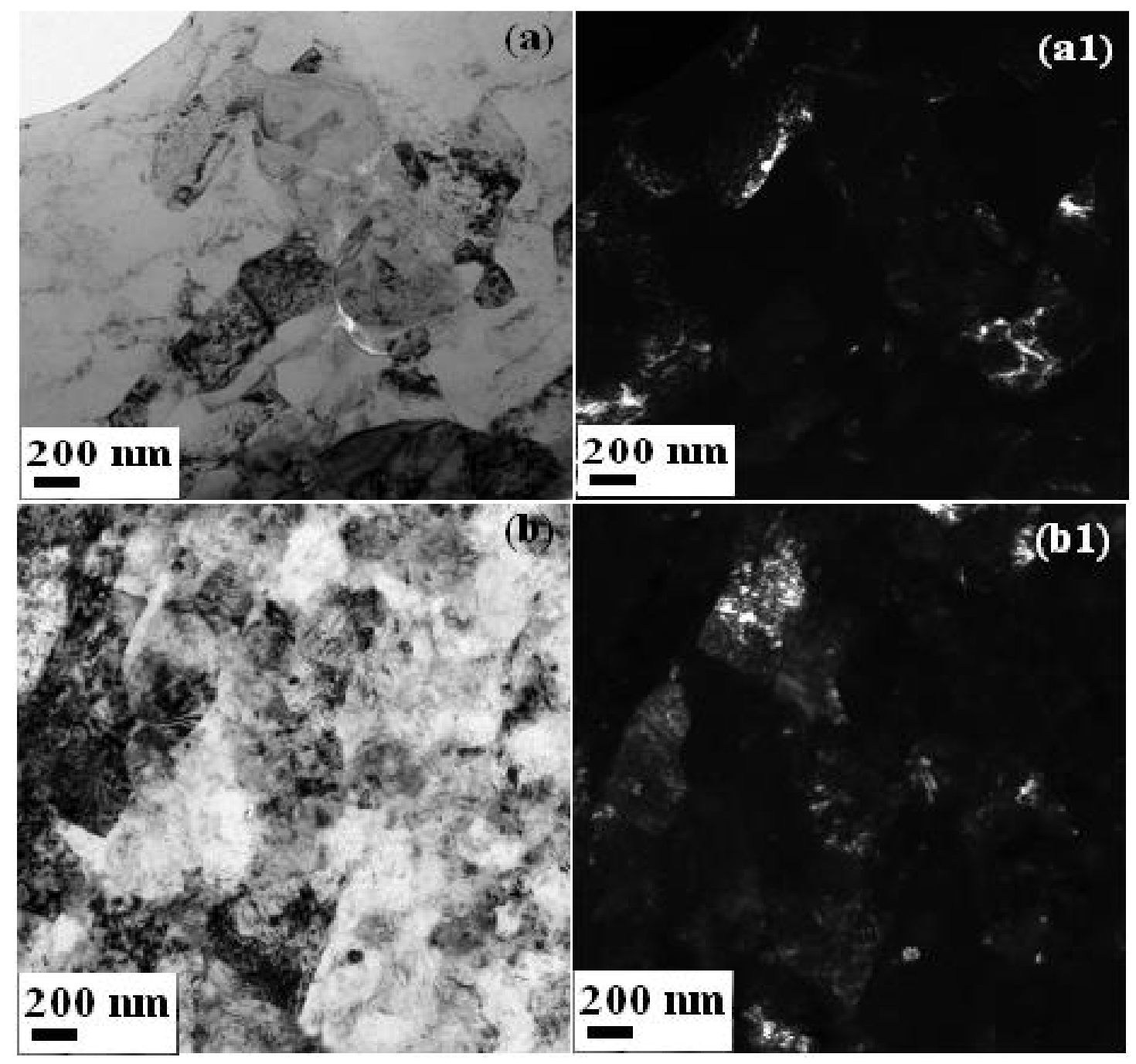




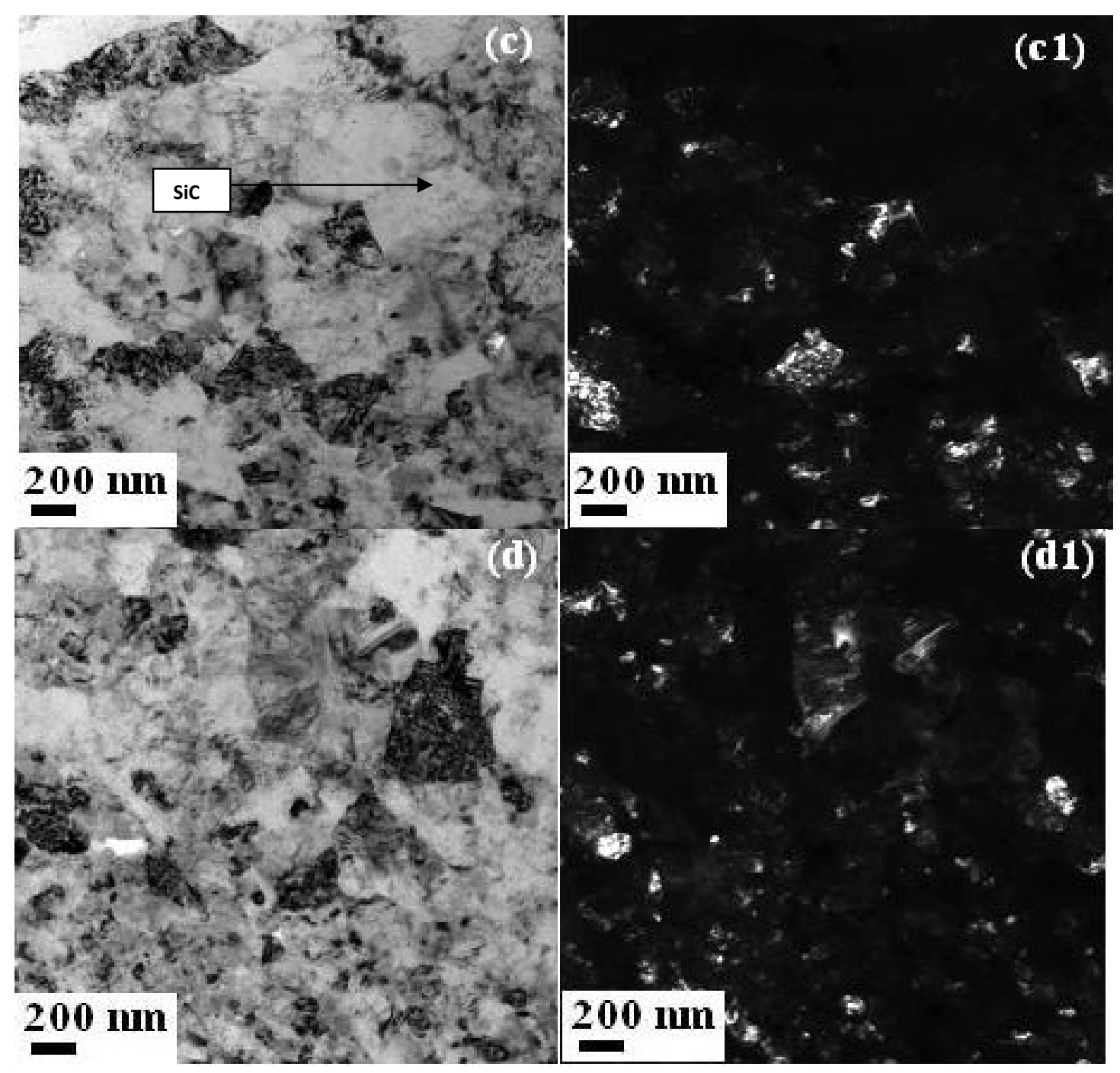

Figure 8 : TEM bright field and dark field images of Al-4wt\%Cu-(2.5-10)vol.\% SiC nanocomposites bars produced by PCE (a) and (a1) $2.5 \mathrm{vol.} \% \mathrm{SiC}$,(b) and (b1) $5 \mathrm{vol} . \%$ $\mathrm{SiC},(\mathrm{c})$ and (c1) 7.5vol.\% SiC,(d) and (d1) 10vol.\% SiC. 


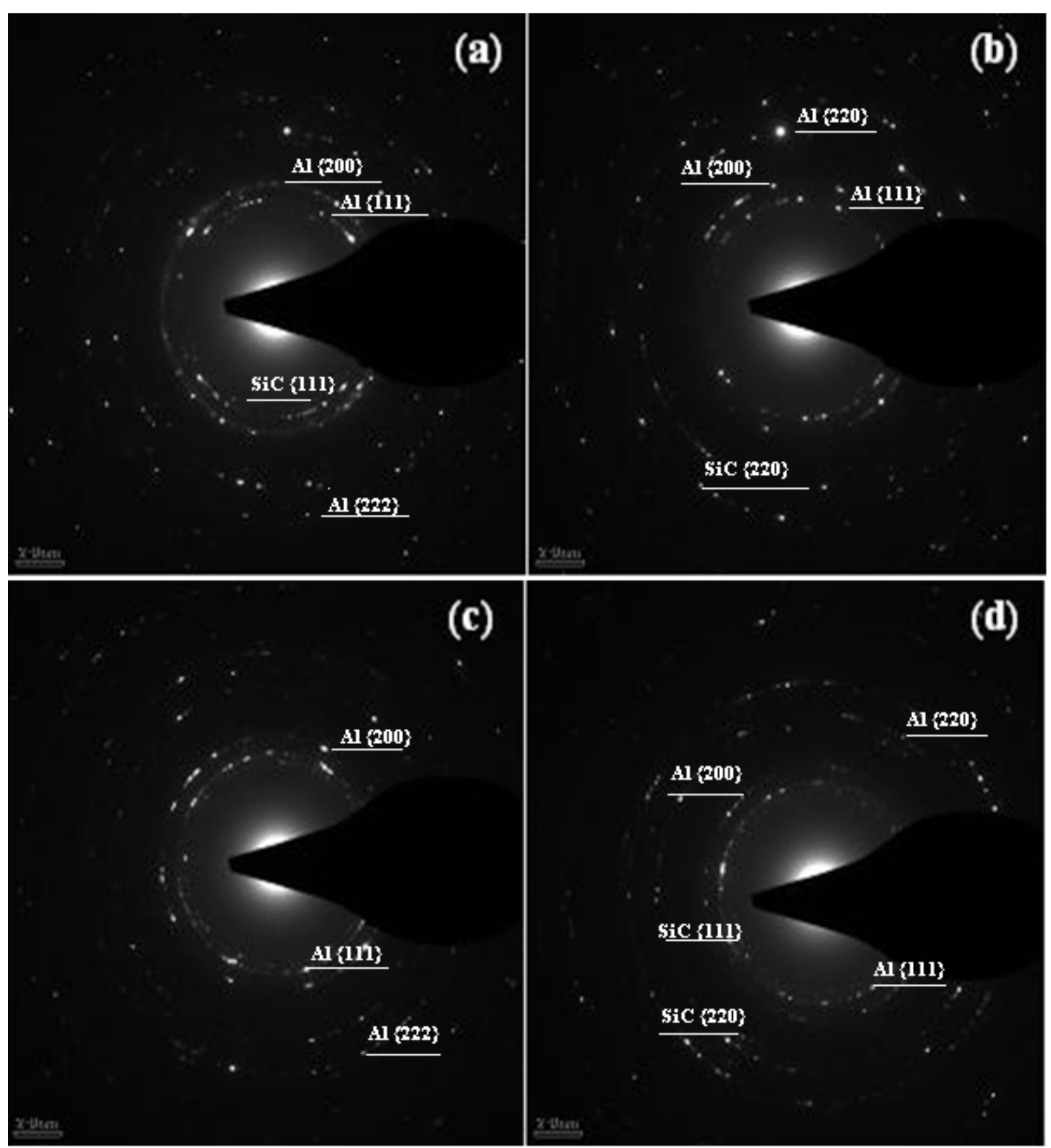

Figure 9: Selected area electron diffraction patterns corresponding to the TEM images in Figure 5.14: (a) Al-4wt\%Cu-2.5vol.\% SiC ,(b) Al-4wt\%Cu-5vol.\% SiC,(c) Al-4wt\%Cu7.5vol.\% SiC,(d) Al-4wt\%Cu-10vol.\% SiC .

Figure 10 shows the tensile engineering stress-strain curves of specimens cut from the extruded bars. With $2.5 \mathrm{vol}$. \% SiC, the extruded bar showed a yield strength, ultimate tensile strength (UTS) and plastic strain to fracture of $98 \mathrm{MPa}, 168 \mathrm{MPa}$ and $6.8 \%$, respectively. By increasing the volume fraction of $\mathrm{SiC}$ nanoparticles to $5 \%$ the yield strength and UTS of the extruded bar increased dramatically $391 \mathrm{MPa}$ and $400 \mathrm{MPa}$, respectively, but the plastic strain to fracture of the extruded bar decreased to $1.2 \%$. With a further increase in the volume fraction of SiC nanoparticles to 7.5 or 10 vol.\%, the tensile test specimens fractured prematurely at stresses of $270 \mathrm{MPa}$ and 
$325 \mathrm{MPa}$ respectively, without showing any plastic yielding. Figure 11 shows the typical fracture surfaces of the tensile test specimens cut from the $\mathrm{Al}-4 \mathrm{wt} \% \mathrm{Cu}-(2.5-$ 10) vol. \% $\mathrm{SiC}$ bars produced by PCE. It can be seen that the fracture of the $\mathrm{Al}-4 \mathrm{wt} \% \mathrm{Cu}$ (2.5 and 5) vol. \% SiC nanocomposite specimens occurred through ductile fracture of the Al matrix, with the fracture surfaces showing dimples and ligaments. It appeared that with increasing the $\mathrm{SiC}$ nanoparticle content from 2.5 vol. \% to $5 \%$, the depth of the dimples and height of the ligaments became significantly smaller, as shown in Figure 11 (a) and (b). The fracture surfaces of the Al-4wt\%Cu- 7.5 and 10) vol. \% $\mathrm{SiC}$ nanocomposite

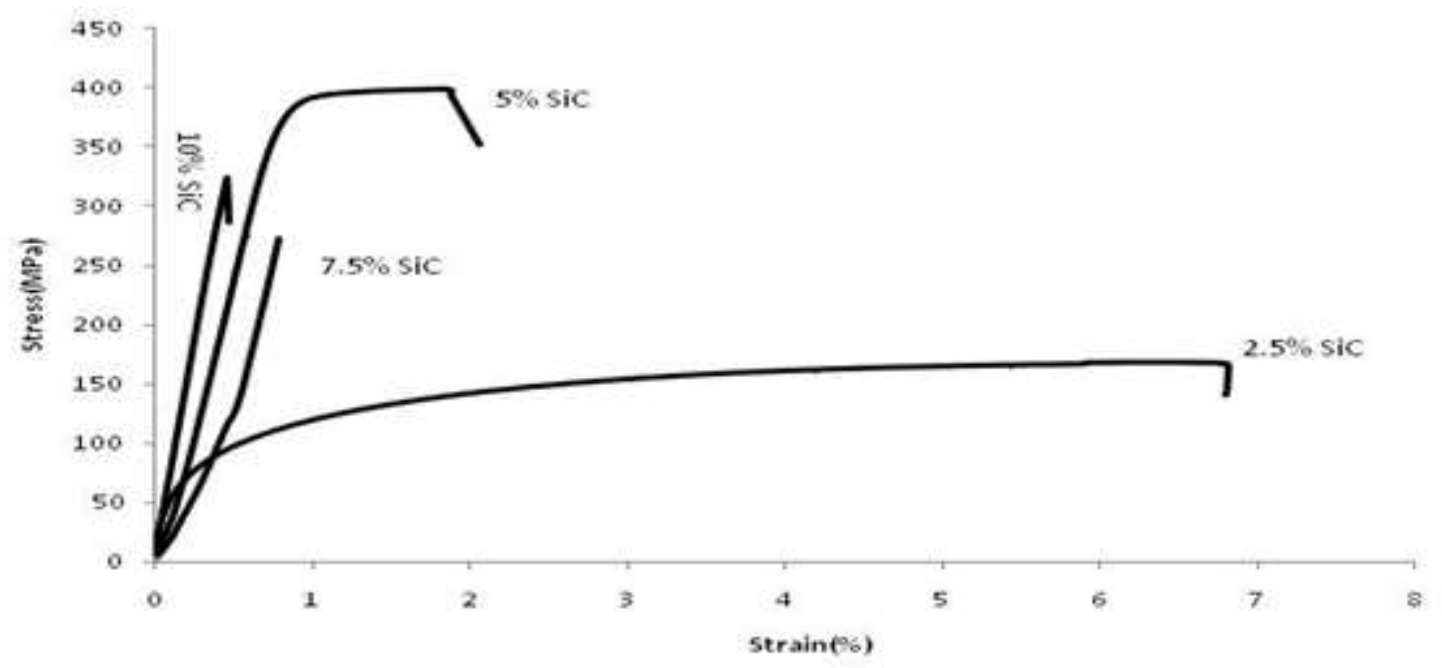

specimens were very flat, suggesting that their fracture was brittle in nature. To reveal more information about the nature of the bonding between the powder particles, the longitudinal sections of the fractured specimens just below the fracture surfaces were also examined using SEM, as shown in Figure 12. It can be seen that only a few cavities (indicated by the arrows) formed near the fracture surfaces during tensile deformation and fracture of the specimens.The shapes of the cavities suggest that they were not caused by separation of neighbouring powder particles due to weak interparticle bonding in the broken tensile test specimens.

\section{Figure 10 : Tensile stress-strain curves of specimens cut from $\mathrm{Al}-4 \mathrm{wt} \% \mathrm{Cu}-(2.5-10)$ vol. $\%$ SiC bars produced by PCE.}

This work has shown that with increasing the volume fraction of $\mathrm{SiC}$ nanoparticles, the microstructure of the $\mathrm{Al}-4 \mathrm{wt} \% \mathrm{Cu}$ matrix of the bulk nanocomposite samples becomes fine. There are two reasons for this. The first reason is that an increase in the content of $\mathrm{SiC}$ nanoparticle content in the starting powder microstructure increases the effectiveness of HEMM, causing the microstructure of the nanocomposite powder produced by HEMM to be finer, as confirmed by TEM examination of the milled powder particles ${ }^{16}$. The second reason is that the thermal stability of the microstructure of the Al-4wt\%Cu matrix of the nanocomposites increases with the increasing volume fraction of $\mathrm{SiC}$ nanoparticles due to the increased Zenerdrag effect of nanoparticles to resist the movement of grain boundaries. This effect leads to slower rate of microstructural coarsening with increased content of $\mathrm{SiC}$ nanoparticles.

As expected, the yield strength of the bulk nanocomposite samples increases significantly from 98 to $391 \mathrm{MPa}$ with increasing volume fraction of the $\mathrm{SiC}$ from 2.5 to 5 vol. \%, showing that $\mathrm{SiC}$ nanoparticles are effective in strengthening the materials. In the meantime, the further refinement of the microstructure of the Al$4 \mathrm{wt} \% \mathrm{Cu}$ matrix can also contributes to the 
increase of the yield strength. The high effectiveness of these two factors in strengthening the composite is also reflected by the observation that the yield strength of the ultrafine structured Al4wt\%Cu-5vol.\%SiC nanocomposite (391 $\mathrm{MPa}$ ) is more than 2.5 times higher than that of the coarse structured $\mathrm{Al}-4 \mathrm{wt} \% \mathrm{Cu}-$ 10vol.\%SiC composite with an average particle size of $23 \mu \mathrm{m}^{17}$. The significant decrease in ductility of the bulk nanocomposite samples with the increasing volume fraction of $\mathrm{SiC}$ nanoparticles, from 2.5 to $5 \%$, may be due to two reasons: the existence of $\mathrm{SiC}$ nanoparticle agglomerates in the microstructure, which makes the formation of cavities under tensile stress easier, and the refinement of microstructure of the $\mathrm{Al}-$ $4 w t \% \mathrm{Cu}$ matrix which makes it easier to lose stability of deformation under tension 18. Similarly, the premature fracture of the $\mathrm{Al}-4 \mathrm{wt} \% \mathrm{Cu}-(7.5$ and 10)vol.\%SiC nanocomposite samples during tensile testing may also be due to the existence of SiC nanoparticle agglomerates in their microstructure, which make it very easy to form cavities under tensile stress. With the total volume fraction of the $\mathrm{SiC}$ nanoparticles being at a high level of 7.5 or $10 \%$, the number of such $\mathrm{SiC}$ nanoparticles agglomerates per unit volume of the sample can be quite high, so it is easy for cracks to form and propagate, causing fracture to occur before macroscopic yielding.
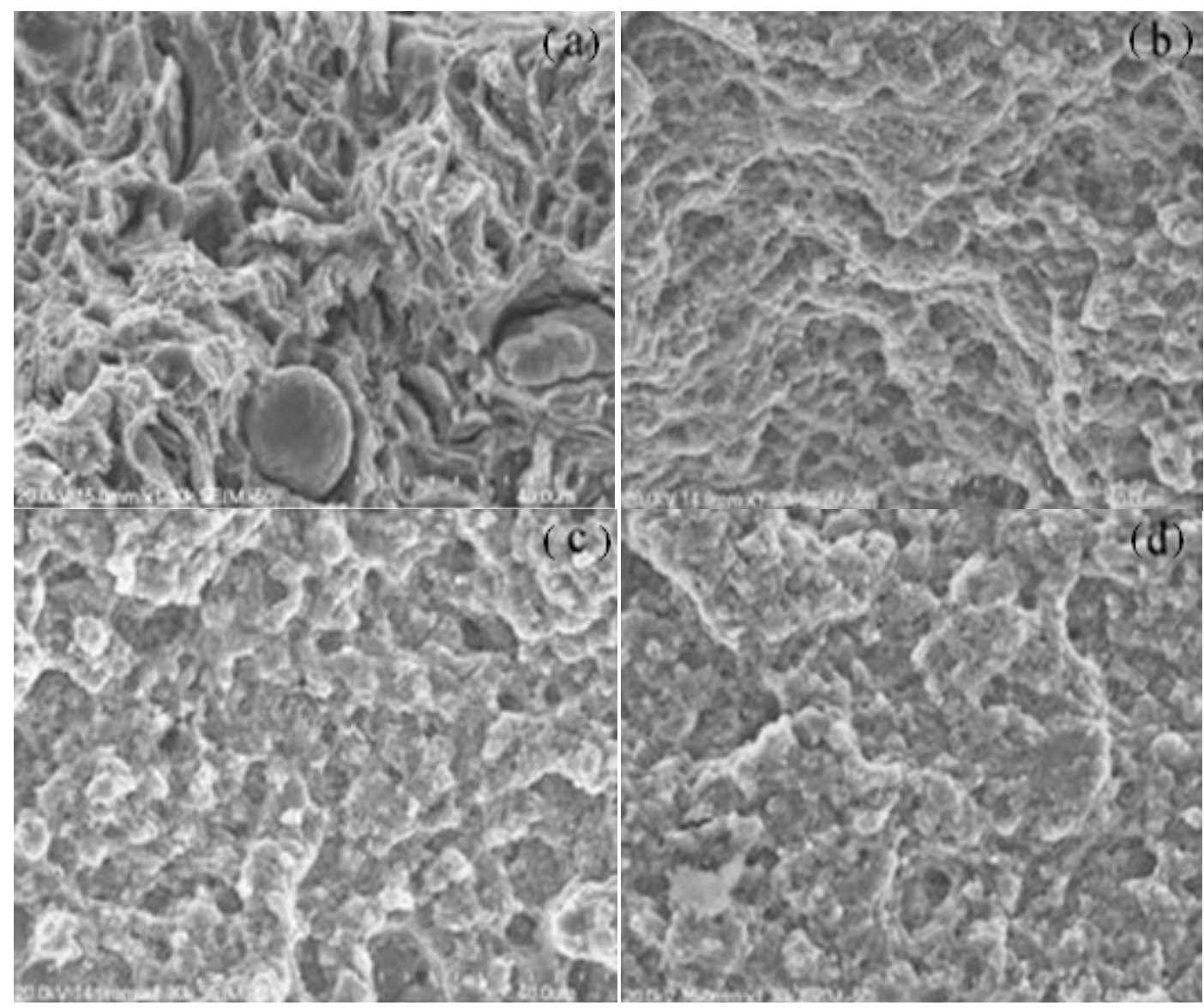

Figure 11: SEM micrographs of the fracture surfaces of the tensile test specimens cut from Al-4wt\%Cu-(2.5-10) vol.\% SiC nanocomposite bars produced PCE: (a) $2.5 \mathrm{vol}$. \%SiC (b) 5 vol. \%SiC (c) 7.5vol. \%SiC (d) 10vol. \%SiC. 

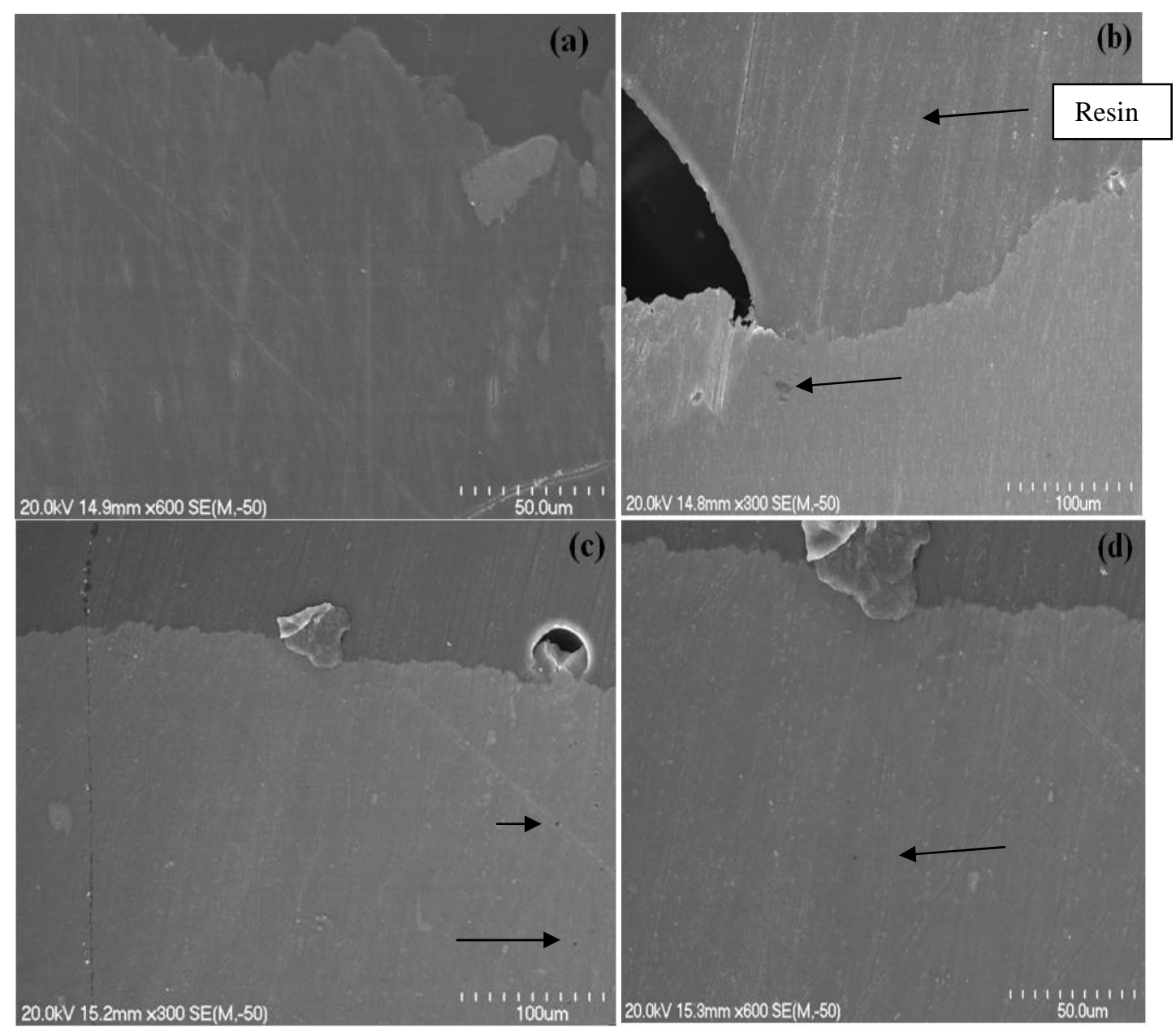

Figure 12: SEM micrographs of the longitudinal sections just below the fracture surfaces of the tensile test specimens cut from the $\mathrm{Al}-4 \mathrm{wt} \% \mathrm{Cu}-(2.5-10) \mathrm{vol} . \% \mathrm{SiC}$ nanocomposite bars produced by PCE: (a) $2.5 \mathrm{vol} . \% \mathrm{SiC}$; (b) $5 \mathrm{vol} . \% \mathrm{SiC}$; (c) $7.5 \mathrm{vol} . \% \mathrm{SiC}$; (d) $10 \mathrm{vol} . \% \mathrm{SiC}$.

\section{Conclusion}

Ultrafine structured $\mathrm{Al}-4 \mathrm{wt} . \% \mathrm{Cu}-(2.5-10)$ vol. \% SiC nanocomposite bars have been produced by a combination of high energy ball milling (HEMM) of mixtures of $\mathrm{Al}$ and $\mathrm{Cu}$ powders and $\mathrm{SiC}$ nanopowder followed by consolidation of the milled powder. Increasing the volume fraction of $\mathrm{SiC}$ nanoparticles from 2.5 to $5 \%$ causes the yield strength, ultimate tensile strength and microhardness of the nanocomposites to increase from $98 \mathrm{MPa}, 168 \mathrm{MPa}$ and 104 $\mathrm{HV}$ to $391 \mathrm{MPa}, 400 \mathrm{MPa}$ and $205 \mathrm{HV}$, showing the high effectiveness of $\mathrm{SiC}$ nanoparticles and microstructure refinement in strengthening the material. However, the ductility decreases from $6.8 \%$ to $2 \%$, possibly due to the existence of $\mathrm{SiC}$ nanoparticle agglomerates in the Al-
$4 \mathrm{wt} \% \mathrm{Cu}-5 \mathrm{vol} \% \mathrm{SiC}$ nanocomposite. The ultrafine structured $\mathrm{Al}-4 \mathrm{wt} \% \mathrm{Cu}-(7.5$ and 10)vol.\%SiC nanocomposite bars fractured prematurely during tensile testing. The possible reason for this may be the existence of $\mathrm{SiC}$ nanoparticles agglomerates in their microstructure

\section{References}

1. Monazzah A.H, Simchi A. and Reihani S.M.S.(2010) " Creep behaviour of hot extruded $\mathrm{Al}-\mathrm{Al}_{2} \mathrm{O}_{3}$ nancomposite powder," Material Science and Engineering A, 527, 2567-2571.

2. Huang Y.G, Chen Z.G and Zheng Z.Q. (2011) "A conventional thermo-mechanical process of $\mathrm{Al}-\mathrm{Cu}-\mathrm{Mg}$ alloy for increasing 
ductility while maintaining high strength," Scripta Materialia, 64,382-385.

3. Ahamed H. and Senthilkumar V. (2010) "Role of nano-size reinforcement and milling on the synthesis of nanocrystalline aluminium alloy composites by mechanical alloying," Journal of Alloys and Compounds, 505,772-782.

4. Alizadeh M. and Paydar M.H. (2010) "Fabrication of nanostructure $\mathrm{Al} / \mathrm{SiC}_{\mathrm{p}}$ composite by accuulative rollbonding(ARB) process," Journal of Alloys and Compounds,492,231-235.

5. Wang Z., Song M., Sun C., and Y. He. (2011) "Effect of particle size and distribution on the mechanical properties of $\mathrm{SiC}$ reinforced $\mathrm{Al}-\mathrm{Cu}$ alloy composite," Material Science and Engineering A, 528, 1131-1137.

6. Kollo L., Leparoux M., Bradbury C.R., Jaggi C., Carreno-Morelli E., and RodriguezArbaizar M. (2010) "Investigation of planetary milling for nano-silicon carbide reinforced aluminium metal matrix composite," Journal of Alloys and Compounds, 489, 394-400.

7. Gazawi A., Zhang D.L., Pickering K.L. , and Mukhtar A. (2011) "Microstructure and Mechanical Behaviour of Ultrafine Grained Al-4wt\%Cu-(2.5-10) vol.\% SiC Metal Matrix Composites Produced by Powder Compact Forging," Advanced Materials Research, 275, 208-213.

8. Kamrani S., Riedel R., Reihani S.M.S., and Kleebe H.J. (08/2007) "Effect of Reinforcement Volume Fraction on the Mechanical Properties of Al-SiC Nanocomposites Produced by Mechanical Allyoing and Consolidation," Powder Metallurgy, 50(3), 276-282.

9. Goussous S., Xu W. and Xia K. (2010) "Developing aluminium nancomposites via severe plastic deformation," Journal of Physics Conference, 240.

10. Rahimian M., Ehsani N., Parven N., and Baharvandi H.R. (2009) "The effect of particle size, sintering temperature and sintering time on the properties of Al-
Al203 composites, made by powder metallurgy," Journal of Materials Processing and Technology, 209, 53875393.

11. Hesabi Z.R., Simchi A., Reihani S.M.S , and Simancik F. (2010) "Fabrication and characterization of ultrafine-grained Al5 vol. $\% \mathrm{Al}_{2} \mathrm{O}_{3}$ nanocomposite," International Journal of Nanomanufacturing," 5, 341-351.

12. Narayanasamy R., Ramesh T., and Prabhakar M.(2009) "Effect of particle size of $\mathrm{SiC}$ in aluminium matrix on workability and strain hardening behaviour of $\mathrm{P} / \mathrm{M}$ composite," Materials Science and Engineering A, 504,13-23.

13. Ogel B. and Gurbuz R. (2001) "Microstructural characterization and tensile properties of hot pressed $\mathrm{Al}-\mathrm{SiC}$ composites prepared from pure $\mathrm{Al}$ and $\mathrm{Cu}$ powders," Materials Science and Engineering A, 301, 213-220.

14. Kollo L., Leparoux M., Bradbury C.R., Veinthal R., Jaggi C., Carreno-Morelli E., Rodrigues- Arbaizar M. (2010) "Investigation of planetary milling for nano-silicon carbide reinforced aluminium metal matrix composites," Journal of Alloys and Compounds, 489, 394-400.

15. Kollo L., Bradbury C.R., Veinthal R., Jaggi C., Carreno-Morelli E., Leparoux M. (2011) "Nano-silicon carbide reinforced aluminium produced by high energy milling and hot consolidation," Materials Science and Engineering A, 528, 66066615.

16. Amro A. Gazawi, Deliang Zhang, Charlie Kong, Paul Munroe, unpublished research.

17. Gupta M.,Lai M.O. and Soo C.Y. (1996) "Effect of type of processing on the microstructural features and mechanical properties of $\mathrm{Al}-\mathrm{Cu} / \mathrm{SiC}$ metal matrix composites," Materials Science and Engineering A, 210, 114-122.

18. Departement of Materials science and Engineering, John Hopkins University.(2003) "Nanocrystalline materials: controlling plastic instability." Nature Materials, 2(1), 7-8. 